\title{
The Histological Variants of Urothelial Carcinoma of the Bladder: It Is Affecting the Prognosis?
}

\author{
Souhail Regragui 1,2, Mohammed Alae Touzani ${ }^{1,2^{*}}$ (D), Amine Slaoui1,2, Anas Mehedra ${ }^{1,2}$, \\ Hafsa Elouazzani ${ }^{3}$, Tariq Karmouni 1,2, Khalid El Khader ${ }^{1,2}$, Abdellatif Koutani',2, \\ Najat Mahassini ${ }^{3}$, Ahmed Ibn Attya Andaloussi',2 \\ ${ }^{1}$ Faculty of Medicine and Pharmacy, Mohammed 5 University, Rabat, Morocco \\ 2“B” Urology Department, Ibn Sina Hospital, Rabat, Morocco \\ ${ }^{3}$ Pathology Department, Ibn Sina Hospital, Rabat, Morocco \\ Email: *medalaet@gmail.com
}

How to cite this paper: Regragui, S., Touzani, M.A., Slaoui, A., Mehedra, A., Elouazzani, H., Karmouni, T., El Khader, K., Koutani, A., Mahassini, N. and Andaloussi, A.I.A. (2020) The Histological Variants of Urothelial Carcinoma of the Bladder: It Is Affecting the Prognosis? Open Journal of Pathology, 10, 24-34.

https://doi.org/10.4236/ojpathology.2020.1 $\underline{01003}$

Received: December 1, 2019

Accepted: December 30, 2019

Published: January 3, 2020

Copyright $\odot 2020$ by author(s) and Scientific Research Publishing Inc. This work is licensed under the Creative Commons Attribution International License (CC BY 4.0).

http://creativecommons.org/licenses/by/4.0/

\section{(c) (i) Open Access}

\begin{abstract}
Urothelial carcinomas (UC) are likely to have particular morphological features that distinguish them from the typical form. These original aspects are called "histological variants of urothelial carcinoma". They can constitute all or part of the tumor and concern mainly muscle invasive UC and high grade. Their frequency varies according to the type, but the knowledge of these variants is essential because of the diagnostic difficulties, and the implication of their presence on the prognosis.
\end{abstract}

\section{Keywords}

Urothelial Carcinoma, Variants, Prognosis

\section{Introduction}

Urothelial carcinomas (UC) are likely to have particular morphological features that distinguish them from the typical form. These original aspects are called "histological variants of urothelial carcinoma". They can constitute all or part of the tumor and concern mainly the muscle-invasive and high grade UC [1]. Their frequency is variable depending on the type (some variants are very exceptional). Knowing these variants is important because of the diagnostic difficulties, and the implication of their presence on prognosis [2]. Through this literature review, we present the different epidemiological, clinical, histological, prognostic and therapeutic aspects of each histological variant of urothelial carcinoma. 


\section{Histological Variants}

\subsection{The Differentiations}

Urothelium has a strong metaplastic power, which is expressed during chronic inflammatory processes as well as in tumor proliferations. Urothelial carcinoma with a differentiation occurs when the metaplastic component represents less than $95 \%$ of the tumoral mass examined [1].

1) The squamous differentiation

The replacement of urothelium by stratified squamous cells can be observed in $10 \%$ to $20 \%$ of CU's of the bladder [2] [3]. Chronic aggression, particularly with tobacco and bilharziasis, seems to favor its appearance. No specific clinical symptoms have been described. Microscopically, nests of polygonal cells can be observed that can show dyskeratoses, keratinization foci or intercellular bridges associated with carcinoma in situ or invasive [4] (Figure 1). For immunohistochemical (IHC) study, L1 antigen and cytokeratin (CK) 14 are positive in areas of squamous differentiation [4]. Areas of abundant squamous differentiation under the microscope are associated with a poor prognosis [5]. Radical cystectomy is the gold standard treatment, but chemotherapy and radiotherapy appear to be ineffective according to some studies [2] [6].

2) Glandular differentiation

Described the first time in the literature in 1968 by GRACE and WINTER [7], glandular differentiation is observed in $6 \%$ of the CU of the bladder [3] [4]. Symptomatology is aspecific. Microscopically, the presence of true glandular spaces within the urothelial component of the tumor is characteristic (Figure 2). It can also take the form of tubular or enteric glands, aligned on a single layer of prismatic epithelium often associated with mucosecreting cells [8] [9]. IHC is characterized by Apomucin MUC5AC and CK7 positive labeling and CDX2, CK20 and villin negative. The prognosis is worse when foci of glandular differentiation are numerous [5]. Radical cystectomy is the treatment of choice and resistancy to radio-chemotherapy is possible [5].

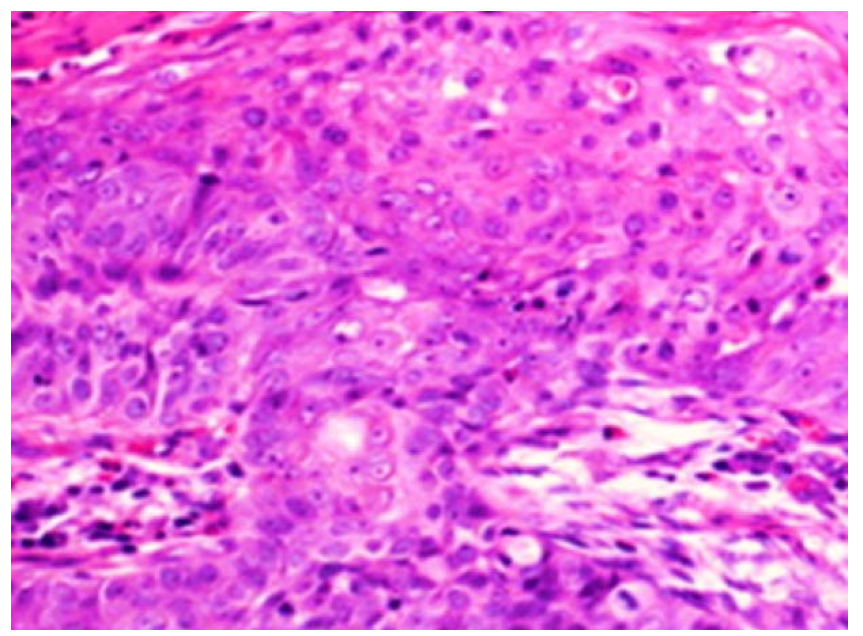

Figure 1. Microscopic appearance of urothelial carcinoma with squamous differentiation. 


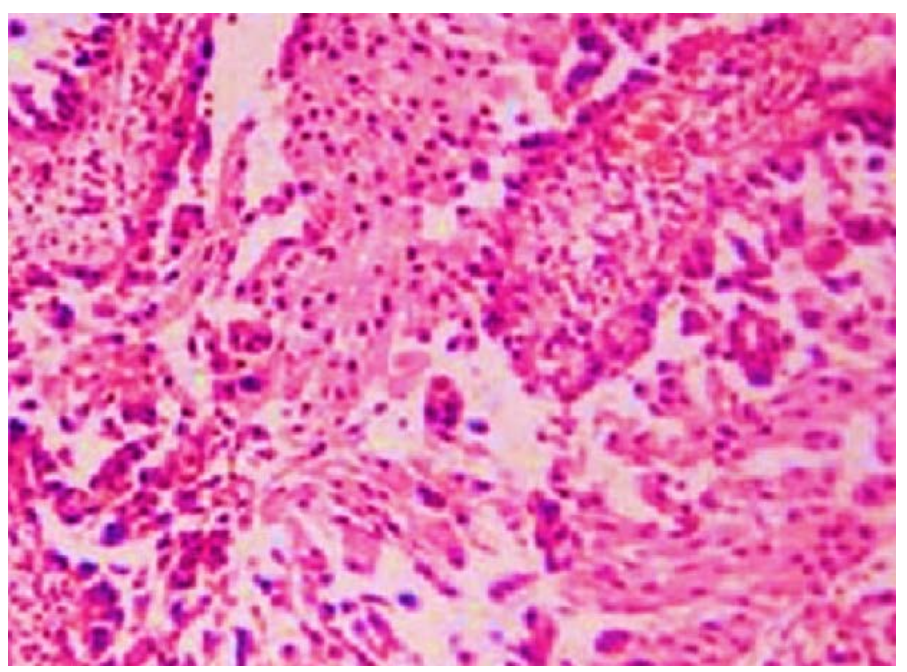

Figure 2. Microscopic appearance of urothelial carcinoma with glandular differentiation.

3) The trophoblastic differentiation

The trophoblastic differentiation has been described for the first time by DJEWITZKI et al. in 1904 [10]. Since then, only about forty cases have been described in the literature [11] [12]. Men are more affected with a sex ratio of 2.4:1 with an average age of 63.9 [13]. In male cases, gynecomastia is frequently observed. The HCG rate is high in almost all cases. Histologically, they are characterized by the presence of cytotrophoblastic-type mononuclear cells or the intermediate trophoblast and multinucleated large cells with abundant eosinophilic cytoplasm of syncytiotrophoblastic appearance. Rarely, this contingent is associated with areas of micropapillary or sarcomatoid differentiation [14] [15] [16]. At IHC, the tumor cells express beta-HCG, human placental lactogen (HPL) and GATA3, but do not show labeling with CK7 and P63, which distinguishes them from cells of the classical urothelial challenge [17]. The prognosis seems to be bad: at the time of diagnosis, about $47 \%$ of cases present metastases [13] [15]. The treatment of these cancers is not well standardized and remains mainly surgical. In addition, it has been reported that HCG secretion is associated with radio-resistancy, which may explain the low efficiency of radiotherapy on this type of tumor [18].

\subsection{Sarcomatoid Carcinoma (Fusiform Cells)}

Sarcomatoid carcinoma with fusiform cells is a variant that is probably less exceptional than the figures in the literature $(0.6 \%-1 \%)$ describe [19] [20]. It mainly affects men (1.7 to 4 men for 1 woman), with an average age of 66.4 years (21 - 91 years) [21] [22]. Some cases have been described at a pT1 stage. Spindle cell carcinoma may be only a partial differentiation of urothelial carcinoma, but in general it constitutes the entire tumor mass [5]. The clinical presentation is aspecific, dominated by hematuria, dysuria, nocturia and acute retention of urine [14] [23]. Macroscopically, these tumors form large polyploid buds protruding into the bladder lumen [5]. Histologically, the fusiform contingent is va- 
riable in appearance, abundance, uniform, epithelioid or heterologous differentiation of chondrosarcoma or osteosarcoma [5] (Figure 3). It merges with the urothelial contingent. Immunolabeling with Cytokeratin and EMA to confirm the epithelial nature is sometimes essential [5] [16]. Markers P63, CK5/6 and HMWCK are positive in $10 \%$ to $40 \%$ of cases. It is a very aggressive variant, generally diagnosed at an advanced stage, and its evolution is unfavorable, with rapid onset of pulmonary or hepatic metastases and a 5-year survival of about 20 to $50 \%$ [21] [24], despite a treatment combining cystectomy and complementary radiotherapy [5]. Most published cases have been treated with radical cystectomy, sometimes associated with postoperative radiotherapy. It would seem that this type of tumor is radiosensitive [21].

\subsection{The Nest Variant}

In 1979, STERN described a variant of urothelial carcinoma with nests contiguous to each other [25]. In 1989, TALBERT and YOUNG describe this entity and give it the name of "nested carcinoma" [26] [27]. This very rare variant (0.3\%) must be known because it can be difficult to identify by a superficial biopsy [1]. Less than one hundred cases have been described in the literature. The age of onset of this tumor does not differ from that of classical urothelial carcinoma [5] [14] [28] [29], with predominance for males. Symptoms are dominated by hematuria, urgency and signs of ureteral obstruction [30]. On resection specimens, cell proliferation leaves a non-atypical flat epithelium on the surface and infiltrates the chorion as small cell nests resembling Von Brünn islands. These cellular nests are rounded, ovoid, or in the shape of a "heart" surrounded by a basement membrane. The cells are relatively regular, not atypical, which is very misleading. Only at the periphery of certain nests and in the deepest nests are atypical cells identified with a large hyperchromatic nucleus [5]. According to the WHO, this variant is considered low grade however, several authors propose

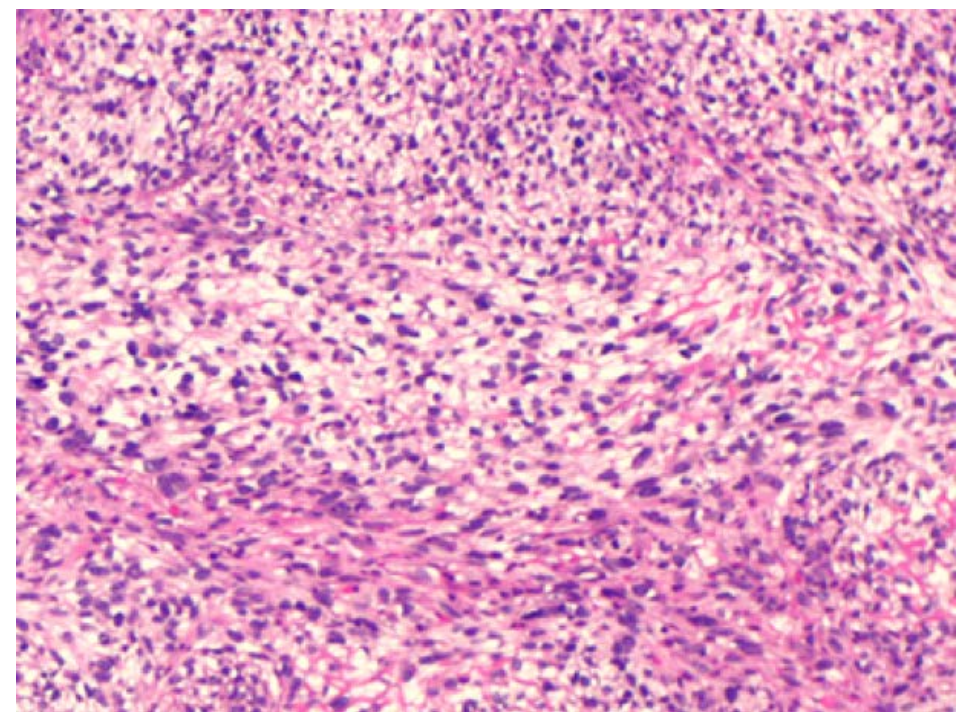

Figure 3. Microscopic appearance of sarcomatoid urothelial carcinoma. 
to reclassify it as high grade [31] [32] [33]. Regarding IHC, overexpression of P53 and MIB-1 has been described [31]. Despite treatment, the evolution is unfavorable with survival between 4 and 40 months after diagnosis [34]. Neoadjuvant chemotherapy appears to increase survival in some patients. Radical cystectomy is the treatment of choice [5] [35] [36].

\subsection{Plasmocytoid Carcinoma}

First described by SAHIN and COLL in 1991 [37] and since then only about 100 cases have been reported in the literature [38]. The diagnosis is most often made at an advanced stage of the disease [38]. According to several authors, the average age at diagnosis is 65 years with a clear male predominance [38] [39]. The plasmocytoid variant of the bladder is rare, its incidence varies between $0.5 \%$ and $2.7 \%$ of urothelial carcinomas [40] [41]. According to WASCO et al., the symptomatology is not specific [35]. Microscopically, it is a poorly differentiated or even undifferentiated carcinoma, and is often associated with a conventional high-grade UC or sarcomatoid carcinoma. The tumor cells are diffuse non-cohesive, oval or round with a loose, myxoid stroma, contained in abundant eosinophilic cytoplasm and eccentric nuclei (Figure 4). The plasmocytoid component can represent between $30 \%$ to $100 \%$ of the tumor [5]. This variant is characterized by cell labeling with anti-CK7, CK20, AE1/AE3, EMA and CD138, associated with a negativity of the labeling for LCA, S100, HMB45 and CD79- $\alpha$ [40] [41]. The prognosis in advanced forms is poor [42] [43]. Cystectomy is the treatment of choice associated with adjuvant chemotherapy [42] [44]. Dayyani reports a median overall survival of 45.8 months [42].

\subsection{The Micropapillary Variant (VMCP)}

First described in 1994 by AMIN et al. in a series of patients [45]. Micropapillary carcinoma is a rare variant $(0.6 \%$ to $2 \%)$ of urothelial carcinoma. The age of onset

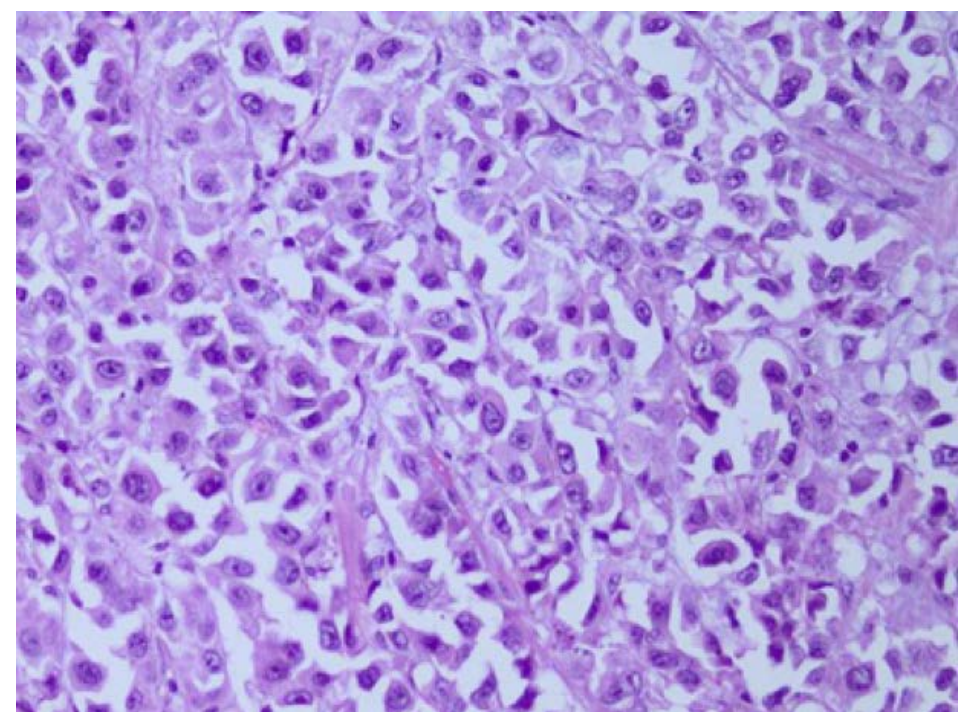

Figure 4. Microscopic appearance of plasmocytoid urothelial carcinoma. 
is between 50 and 90 years with an average age of 66 years with marked predominance in men [4] [46]. Clinical manifestations are dominated by hematuria [30]. Histologically, the tumor infiltrates the wall in the form of masses of papillary masses underlined by retraction spaces. Tumor proliferation consists of abundant cytoplasmic eosinophilic cells with irregular nuclei and a high nucleocytoplasmic ratio. The micropapillary areas can represent $10 \%$ to $90 \%$ of the tumor. Lymphatic and vascular emboli are frequently associated with them. The immunohistochemical study is useful, with a panel of antibodies including: uroplakin, CK20, TTF-1 (to exclude thyroid origin), estrogen receptor, WT-1, or PAX8, and mammaglobin (to exclude an origin metastatic cancer of the ovary or breast cancer). In case of need, the best markers in favor of a urothelial origin are uroplakin, GATA3 and CK20 [47] [48]. The expression of MUC1 is limited to the basal pole of cells whereas it can be intracytoplasmic or intercellular in conventional UC [47]. It is always a very high grade, advanced (>pT2) tumor with a poor prognosis (5-year survival of less than 25\%) [35]. Tumor stage and survival are correlated with the proportion of the micropapillary quota [47] [48] [49]. According to several teams, it is strongly recommended to perform a second resection before treatment, in search of a muscular invasion unnoticed although this is controversial [49]. Some teams propose a cystectomy from the outset to improve patient survival [48].

\subsection{Lymphoepithelial Carcinoma}

First described in 1991 by ZUKERBERG et al. [50], it is a rare variant (0.4 to $1.6 \%)$ of urothelial carcinoma [51]. It occurs mainly in the elderly with a marked predominance in men [4] [51]. According to ALLENDE et al., the symptomatology is dominated by hematuria [52]. The microscopic study describes a high-grade minority urothelial contingent surrounded by an abundant inflammatory stroma, excessively rich in lymphocytes, plasma cells, histiocytes, and polymorphonuclear neutrophils. Epithelial cells express cytokeratin (AE1/AE3) as well as differentiation markers CK7 and CK8 but rarely CK20. The lymphoid stroma expresses CD45 with CD20+ and CD3 components. This rare variant is characterized by an unfavorable evolution, a discovery often at an advanced stage $(>\mathrm{pT} 2)$ at the time of diagnosis and a survival rate at 5 years after cystectomy of 57\% [5] [53]. Pure forms respond well to chemotherapy [51] [54].

\subsection{Microcystic Carcinoma}

Microcystic urothelial carcinoma resembles carcinoma "in nests" with images of cystic cavitation of "nests" [9] [55]. The difficulty is to distinguish with a benign lesion such as cystic and glandular cystitis and nephrogenic metaplasia [55]. The diagnosis of malignancy is based on the presence of cytonuclear atypia and/or the infiltrative nature of the lesion and/or the existence of a more typical urothelial carcinoma contingent. The aggressive reputation of microcystic carcinoma stems from the fact that it is difficult to recognize on shallow specimens and 
is therefore diagnosed at a late stage. At the slightest doubt, one must know how to ask for a new resection [55].

\subsection{Giant Cell Carcinoma}

It is an exceptional variant, by definition always associated with conventional urothelial carcinoma [56]. It is composed of poorly differentiated, pleomorphic cells with abundant eosinophilic or amphophilic cytoplasm. Nuclear atypias are marked, with many nucleoli, like giant cells observed in pulmonary neoplasia [56] [57]. At IHC, epithelial markers are positive, including cytokeratin and EMA, sometimes for HCG [56] [57].

\section{Conclusion}

A good histological classification of invasive urothelial carcinoma is essential for a better knowledge of the prognosis as well as the possible therapeutic strategies. One of the major difficulties in understanding UC is its extremely heterogeneous genetic profile. It is already being seen that urothelial carcinoma will not be treated in the future solely by histological data alone, but that gene profiles start to play a major role, helping to select chemo-sensitive patients, but also to avoid overly heavy, ineffective treatments for chemo-resistant patients. Nevertheless, the histology will keep an important place to allow a quick diagnosis, and at a lower cost.

\section{Acknowledgements}

We would like to thank the Pathology Department of the Ibn Sina Teaching Hospital for sharing the histopathological images.

\section{Conflicts of Interest}

The authors declare no conflicts of interest regarding the publication of this paper.

\section{References}

[1] Billerey, C., Sibony, M., Gattegno, B. and Chopin, D. (2001) Anatomie pathologique des tumeurs superficielles de la vessie. Progrès en Urologie, 11, 805-863.

[2] Young, R.H. and Eble, J.N. (1991) Unusual Forms of Carcinoma of the Urinary Bladder. Human Pathology, 22, 948-965. https://doi.org/10.1016/0046-8177(91)90003-8

[3] Lopez-Beltran, A., Martin, J., Garcia, J. and Toro, M. (1988) Squamous and Glandular Differentiation in Urothelial Bladder Carcinomas. Histopathology, Histochemistry, and Immunohistochemical Expression of Carcinoembryonic Antigen. Histology and Histopathology, 3, 63-68.

[4] Eble, J., Epstein, J. and Sesterhann, I. (2004) Pathology and Genetics of Tumours of the Urinary System and Male Genital Organs. IARC Press, Lyon.

[5] Magi-Galluzzi, C., Falzarano, S.M. and Zhou, M. (2008) Urothelial Carcinoma and Its Variants. Surgical Pathology Clinics, 1, 159-209. 
https://doi.org/10.1016/j.path.2008.07.004

[6] Black, P.C., Brown, G.A. and Dinney, C.P. (2009) The Impact of Variant Histology on the Outcome of Bladder Cancer Treated with Curative Intent. Urologic Oncology: Seminars and Original Investigations, 27, 3-7.

https://doi.org/10.1016/j.urolonc.2007.07.010

[7] Grace, D.A. and Winter, C.C. (1968) Mixed Differentiation of Primary Carcinoma of the Urinary Bladder. Cancer, 21, 1239-1243.

https://doi.org/10.1002/1097-0142(196806)21:6<1239::AID-CNCR2820210627>3.0. $\mathrm{CO} ; 2-\mathrm{E}$

[8] Kunze, E. and Francksen, B. (2002) Histogenesis of Nonurothelial Carcinomas of the Urinary Bladder from Pre-Existent Transitional Cell Carcinomas. A Histopathological and Immunohistochemical Study. Urological Research, 30, 66-78.

https://doi.org/10.1007/s00240-001-0232-3

[9] Kunze, E., Francksen, B. and Schulz, H. (2001) Expression of MUC5AC Apomucin in Transitional Cell Carcinomas of the Urinary Bladder and Its Possible Role in the Development of Mucus-Secreting Adenocarcinomas. Virchows Archiv, 439, 609-615. https://doi.org/10.1007/s004280100429

[10] Djewitzki, W.S. (1904) Primary Chorionepithelioma of the Urinary Bladder in a Male: Report of a Case. Virchows Archiv für pathologische Anatomie und Physiologie und für klinische Medizin, 178, 451-464. https://doi.org/10.1007/BF02058574

[11] Shah, V.M., Newman, J., Crocker, J., Chapple, C.R., Collard, M.J., O’Brien, J.M., et al. (1986) Ectopic Beta-Human Chorionic Gonadotropin Production by Bladder Urothelial Neoplasia. Archives of Pathology \& Laboratory Medicine, 110, 107-111.

[12] Hara, S., Ito, K., Nagata, H., Tachibana, M., Murai, M. and Hata, J. (2000) Choriocarcinoma of the Renal Pelvis: A Case Report. Hinyokika Kiyo, 46, 117-121.

[13] Campbell, P.A. and McKendrick, J. (1999) Choriocarcinoma of the Urinary Bladder. Australian and New Zealand Journal of Surgery, 69, 533-537. https://doi.org/10.1046/j.1440-1622.1999.01607.x

[14] Lopez-Beltran, A. and Cheng, L. (2006) Histologic Variants of Urothelial Carcinoma: Differential Diagnosis and Clinical Implications. Human Pathology, 37, 1371-1388. https://doi.org/10.1016/j.humpath.2006.05.009

[15] Ramakumar, S., Cheville, J.C. and Zincke, H. (1998) Urothelial Carcinoma of the Bladder with Choriocarcinomatous Differentiation A Report of Two Cases and Review of the Literature. Urologic Oncology: Seminars and Original Investigations, 4, 39-42. https://doi.org/10.1016/S1078-1439(98)00030-1

[16] Armah, H.B. and Parwani, A.V. (2007) Sarcomatoid Urothelial Carcinoma with Choriocarcinomatous Features: First Report of an Unusual Case. Urology, 70, 812.E11-812.E14. https://doi.org/10.1016/j.urology.2007.07.050

[17] Paner, G.P., Annaiah, C., Gulmann, C., Rao, P., Ro, J.Y., Hansel, D.E., et al. (2014) Immunohistochemical Evaluation of Novel and Traditional Markers Associated with Urothelial Differentiation in a Spectrum of Variants of Urothelial Carcinoma of the Urinary Bladder. Human Pathology, 45, 1473-1482. https://doi.org/10.1016/j.humpath.2014.02.024

[18] Regalado, J.J. (2004) Mixed Micropapillary and Trophoblastic Carcinoma of Bladder: Report of a First Case with New Immunohistochemical Evidence of Urothelial Origin. Human Pathology, 35, 382-384. https://doi.org/10.1016/j.humpath.2003.09.012

[19] Kundra, V. and Silverman, P.M. (2003) Imaging in Oncology from the University of 
Texas M. D. Anderson Cancer Center: Imaging in the Diagnosis, Staging, and Follow-up of Cancer of the Urinary Bladder. American Journal of Roentgenology, 180, 1045-1054. https://doi.org/10.2214/ajr.180.4.1801045

[20] Wright, J.L., Black, P.C., Brown, G.A., et al. (2007) Differences in Survival among Patients with Sarcomatoid Carcinoma, Carcinosarcoma and Urothelial Carcinoma of the Bladder. Journal of Urology, 178, 2302-2307. https://doi.org/10.1016/j.juro.2007.08.038

[21] Lopez-Beltran, A., Pacelli, A., Rothenberg, H., Wollan, P., Zincke, H., Blute, M., et al. (1998) Carcinosarcoma and Sarcomatoid Carcinoma of the Bladder: Clinicopathological Study of 41 Cases. Journal of Urology, 159, 1497-1503. https://doi.org/10.1097/00005392-199805000-00023

[22] Perret, L., Chaubert, P., Hessler, D. and Guillou, L. (1998) Primary Heterologous Carcinosarcoma (Metaplastic Carcinoma) of the Urinary Bladder: A Clinicopathologic, Immunohistochemical, and Ultrastructural Analysis of Eight Cases and a Review of the Literature. Cancer, 82, 1535-1549.

https://doi.org/10.1002/(SICI)1097-0142(19980415)82:8<1535::AID-CNCR16>3.0.C $\underline{\mathrm{O} ; 2-5}$

[23] Bouchot, O. and Zerbib, M. (2002) Les Traitements des tumeurs rares de la vessie. Progrès en Urologie, 12, 1129-1130.

[24] Moreau, A., Renaudin, K. and Buzelin, F. (2002) Anatomie pathologique des tumeurs non épithéliales infiltrantes de la vessie. Progrès en Urologie, 12, 805-817.

[25] Stern, J.B. (1979) Unusual Benign Bladder Tumor of Brunn Nest Origin. Urology, 14, 288-289. https://doi.org/10.1016/0090-4295(79)90505-3

[26] Talbert, M.L. and Young, R.H. (1989) Carcinomas of the Urinary Bladder with Deceptively Benign-Appearing Foci. A Report of Three Cases. The American Journal of Surgical Pathology, 13, 374-381. https://doi.org/10.1097/00000478-198905000-00004

[27] Compérat, E. (2008) Perspectives 2007 en pathologie vésicale. Cas 6. Carcinome urothélial de haut grade avec composante en nids. Annales de Pathologie, 28, 294-297. https://doi.org/10.1016/j.annpat.2008.06.030

[28] Epstein, J.I., Amin, M.B. and Reuter, V.E. (2004) Bladder Biopsy Interpretation. Lippincott Williams \& Wilkins, Philadelphia, PA.

[29] Lopez-Beltran, A., Requena, M.J., Cheng, L., et al. (2008) Pathological Variants of Invasive Bladder Cancer According to Their Suggested Clinical Significance. BJU International, 101, 275-281. https://doi.org/10.1111/j.1464-410X.2007.07271.X

[30] Zhai, Q.J., Black, J., Ayala, A.G. and Ro, J.Y. (2007) Histologic Variants of Infiltrating Urothelial Carcinoma. Archives of Pathology \& Laboratory Medicine, 131, 1244-1256.

[31] Lin, O., Cardillo, M., Dalbagni, G., Linkov, I., Hutchinson, B. and Reuter, V.E. (2003) Nested Variant of Urothelial Carcinoma: A Clinicopathologic and Immunohistochemical Study of 12 Cases. Modern Pathology, 16, 1289-1298. https://doi.org/10.1097/01.MP.0000094091.04541.FC

[32] Humphrey, P.A., Moch, H., Cubilla, A.L., Ulbright, T.M. and Reuter, V.E. (2016) The 2016 WHO Classification of Tumours of the Urinary System and Male Genital Organs-Part B: Prostate and Bladder Tumours. European Urology, 70, 106-119. https://doi.org/10.1016/j.eururo.2016.02.028

[33] Drew, P.A., Furman, J., Civantos, F. and Murphy, W.M. (1996) The Nested Variant of Transitional Cell Carcinoma: An Aggressive Neoplasm with Innocuous Histology. Modern Pathology, 9, 989-994. 
[34] Holmang, S. and Johansson, S.L. (2001) The Nested Variant of Transitional Cell Carcinoma-A Rare Neoplasm with Poor Prognosis. Scandinavian Journal of Urology and Nephrology, 35, 102-105. https://doi.org/10.1080/003655901750170425

[35] Wasco, M.J., Daignault, S., Bradley, D. and Shah, R.B. (2010) Nested Variant of Urothelial Carcinoma: A Clinicopathologic and Immunohistochemical Study of 30 Pure and Mixed Cases. Human Pathology, 41, 163-171. https://doi.org/10.1016/j.humpath.2009.07.015

[36] Samaratunga, H. and Delahunt, B. (2012) Recently Described and Unusual Variants of Urothelial Carcinoma of the Urinary Bladder. Pathology, 44, 407-418. https://doi.org/10.1097/PAT.0b013e3283560172

[37] Sahin, A.A., Myhre, M., Ro, J.Y., et al. (1991) Plasmacytoid Transitional Cell Carcinoma. Report of a Case with Initial Presentation Mimicking Multiple Myeloma. Acta Cytologica, 35, 277-280.

[38] Benazzouz, M.H., Essatara, Y., Elsayegh, H., Iken, A., Benslimane, L., Znati, K. and Nouini, Y. (2014) Le carcinome urothélial plasmocytoïde de la vessie: Une entité histologique rare au pronostic sombre. Canadian Urological Association Journal, 8, 733-738. https://doi.org/10.5489/cuaj.2017

[39] Wang, Z., Lu, T., Du, L., et al. (2012) Plasmacytoid Urothelial Carcinoma of the Urinary Bladder: A Clinical Pathological Study and Literature Review. International Journal of Clinical and Experimental Pathology, 5, 601-608.

[40] Mai, K.T., Park, P.C., Yazdi, H.M., et al. (2006) Plasmacytoid Urothelial Carcinoma of the Urinary Bladder Report of Seven New Cases. European Urology, 50, 1111-1114. https://doi.org/10.1016/j.eururo.2005.12.047

[41] Ro, J.Y., Shen, S.S., Lee, H.I., et al. (2008) Plasmacytoid Transitional Cell Carcinoma of Urinary Bladder: A Clinicopathologic Study of 9 Cases. The American Journal of Surgical Pathology, 32, 752-757. https://doi.org/10.1097/PAS.0b013e318159af9e

[42] Dayyani, F., Czerniak, B.A., Sircar, K., et al. (2013) Plasmacytoid Urothelial Carcinoma, A Chemosensitive Cancer with Poor Prognosis, and Peritoneal Carcinomatosis. Journal of Urology, 189, 1656-1661. https://doi.org/10.1016/j.juro.2012.11.084

[43] Sakuma, T., Maurin, C., Ujike, T. and Kawano, K. (2011) Variante plasmacytoïde de carcinome urothélial vésical et cancer prostatique: A propos de deux cas. Progrès en Urologie, 21, 891-894. https://doi.org/10.1016/j.purol.2011.02.007

[44] Kaimakliotis, H.Z., Monn, M.F., Cheng, L., et al. (2014) Plasmacytoid Bladder Cancer: Variant Histology with Aggressive Behavior and a New Mode of Invasion along Fascial Planes. Urology, 83, 1112-1116. https://doi.org/10.1016/j.urology.2013.12.035

[45] Amin, M.B., Ro, J.Y., El-Sharkawy, T., et al. (1994) Micropapillary Variant of Transitional Cell Carcinoma of the Urinary Bladder. Histologic Pattern Resembling Ovarian Papillary Serous Carcinoma. The American Journal of Surgical Pathology, 18, 1224-1232. https://doi.org/10.1097/00000478-199412000-00005

[46] Perez-Montiel, D., Hes, O., Michal, M. and Suster, S. (2006) Micropapillary Urothelial Carcinoma of the Upper Urinary Tract: Clinicopathologic Study of Five Cases. American Journal of Clinical Pathology, 126, 86-92. https://doi.org/10.1309/K7MELVFPKQE2RCDL

[47] Samaratunga, H. and Khoo, K. (2004) Micropapillary Variant of Urothelial Carcinoma of the Urinary Bladder: A Clinicopathological and Immunohistochemical Study. Histopathology, 45, 55-64. 
https://doi.org/10.1111/j.1365-2559.2004.01895.x

[48] Willis, D.L., Fernandez, M.I., Dickstein, R.J., Parikh, S., Shah, J.B., et al. (2015) Clinical Outcomes of cT1 Micropapillary Bladder Cancer. Journal of Urology, 193, 1129-1134. https://doi.org/10.1016/j.juro.2014.09.092

[49] Spaliviero, M., Dalbagni, G., Bochner, B.H., Poon, B.Y., Huang, H., Al-Ahmadie, H.A., et al. (2014) Clinical Outcome of Patients with T1 Micropapillary Urothelial Carcinoma of the Bladder. Journal of Urology, 192, 702-707. https://doi.org/10.1016/j.juro.2014.02.2565

[50] Zukerberg, L.R., Harris, N.L. and Young, R.H. (1991) Carcinomas of the Urinary Bladder Simulating Malignant Lymphoma. A Report of Five Cases. The American Journal of Surgical Pathology, 15, 569-576. https://doi.org/10.1097/00000478-199106000-00005

[51] Dinney, C.P., Ro, J.Y., Babaian, R.J. and Johnson, D.E. (1993) Lymphoepithelioma of the Bladder: A Clinicopathological Study of 3 Cases. Journal of Urology, 149, 840-841. https://doi.org/10.1016/S0022-5347(17)36228-6

[52] Allende, D.S., Desai, M. and Hansel, D.E. (2010) Primary Lymphoepithelioma-Like Carcinoma of the Ureter. Annals of Diagnostic Pathology, 14, 209-214. https://doi.org/10.1016/j.anndiagpath.2009.05.007

[53] Amin, M.B. (2009) Histological Variants of Urothelial Carcinoma: Diagnostic, Therapeutic and Prognostic Implications. Modern Pathology, 22, S96-S118. https://doi.org/10.1038/modpathol.2009.26

[54] Amin, M.B., Ro, J.Y., Lee, K.M., et al. (1994) Lymphoepitheliomalike Carcinoma of the Urinary Bladder. The American Journal of Surgical Pathology, 18, 466-473. https://doi.org/10.1097/00000478-199405000-00005

[55] Lopez Beltran, A., Montironi, R. and Cheng, L. (2014) Microcystic Urothelial Carcinoma: Morphology, Immunohistochemistry and Clinical Behavior. Histopathology, 64, 872-879. https://doi.org/10.1111/his.12345

[56] Samaratunga, H., Delahunt, B., Egevad, L., et al. (2016) Pleomorphic Giant Cell Carcinoma of the Urinary Bladder: An Extreme Form of Tumour De-Differentiation. Histopathology, 68, 533-540. https://doi.org/10.1111/his.12785

[57] Lopez-Beltran, A., Blanca, A., Montironi, R., Cheng, L. and Regueiro, J.C. (2009) Pleomorphic Giant Cell Carcinoma of the Urinary Bladder. Human Pathology, 40, 1461-1466. https://doi.org/10.1016/j.humpath.2009.02.016 